Rev. Int. Contam. Ambie. 35 (Environmental Engineering of Sustainable Landscapes) 23-32, 2019

DOI: 10.20937/RICA.2019.35.esp01.03

\title{
A CFD MODEL BASED ON WET DEPOSITION OF LARGE-SCALE NATURAL DRAFT COOLING TOWER
}

\author{
Xuan $\mathrm{WANG}^{1,2}$, Wenjie BAO ${ }^{2}$, Xiaodong $\mathrm{HUANG}^{2}$, Xue WANG ${ }^{2}$, Fenglei DU ${ }^{2}$ \\ Dezhong WANG ${ }^{1}$ and Bo WANG ${ }^{3 *}$
}

${ }^{1}$ School of Mechanical Engineering, Shanghai JiaoTong University, Shanghai 200240, China

${ }^{2}$ Shanghai Nuclear Engineering Research \& Design Institute CO., Ltd, Shanghai, 200233, China

${ }^{3}$ Nuclear and Radiation Safety Center, Ministry of Ecology and Environment, Beijing 100082, China

*Corresponding author: wangbo@chinansc.cn

(Received May 2, 2018; accepted July 31, 2018)

Key words: computational fluid dynamics, cooling tower, wet deposition, nuclear power plant

\begin{abstract}
Traditional research on environmental impacts of natural draft cooling tower in nuclear power plant is mainly based on Gaussian diffusion model or wind tunnel experiments. With the development of modern mainframe computers and turbulence models, CFD method is possible to use for simulating plume drift. CFD software, as it owns powerful computing ability, can simulate and display the plume drift more accurately. In this paper, data from the 1977 Chalk Point Dye Tracer prove CFD simulation to be effective. Also, this paper provides case study on Taohuajiang and Pengze inland nuclear power plants in China. In conclusion, CFD result conforms with the data from the Chalk Point experiment. Compared with SACTI model. As down-wind distance increases, SACTI results decreases faster than CFD. This paper provides a solution that in the lack of field data, CFD will be a powerful tool for assessing environment impacts.
\end{abstract}

Palabras clave: dinámica de fluidos computacional, torre de enfriamiento, depósito húmedo, planta de energía nuclear

\section{RESUMEN}

La investigación tradicional sobre los impactos ambientales de las torres de enfriamiento natural en las plantas nucleares se basa principalmente en los modelos gausianos de difusión o en los experimentos con túneles de viento. Con el desarrollo de las unidades centrales de cómputo y los modelos de turbulencias, es posible usar el método de dinámica de fluidos computacionales (CFD, por sus siglas en inglés) para simular la deriva de la pluma. Con el método CFD, gracias a su poder computacional, se puede simular y desplegar la deriva de la pluma de manera más precisa. En este trabajo se prueba que la simulación de los datos del Chalk Point Dye Tracer de 1977 con el método CFD resultó efectiva. Este trabajo también presenta el caso de estudio de las plantas nucleares chinas continentales de Taohuajiang y Pengze. En conclusión, los resultados con el método CFD concuerdan con los datos del experimento Chalk Point. 


\section{BACKGROUND}

With the rapid development of national economy and the nuclear power industry, nuclear power plant (NPP) has been given a prominent status. Due to lack of water, inland NPP sites often are chosen to be located in mountainous region. Large-scale natural drift cooling towers will form shadow, salt deposits, fog and ice, which will further affect local environment, road safety and housing conditions. How to give quantitative analysis of these effects become a big issue. In China, National Nuclear Safety Administration (NNSA) issued a "Nuclear power plant environmental impact report format and content (NEPA-RG1)". This regulation has clearly stated that cooling tower impact on the environment must be included (Ammar and Farag 2016, Poppenga and Worstell 2016).

Due to the tough terrain around inland NPP, wind field near the ground becomes very changeable, and plume drifts from cooling towers is always of great uncertainty. (Well and Brower 1984, Nguyen et al. 1997). Plume diffusion in atmosphere is retrained by the factors, including wind direction, wind speed, turbulence, temperature, stability and terrain conditions. At present, Gaussian model and other simple dispersion models, or $\mathrm{SF}_{6}$ field experiments and wind tunnel experiments are used to calculate plume concentration. In mountainous area, airflow in the horizontal and vertical directions are not flat, and flow filed distribution is also uneven, and mainly in the shape and transport path. Therefore, local concentration distribution is different form that of other places, so the traditional Gaussian model has been unable to solve this kind of problem (Zhishan and Jinping 1998, Zongkai and Xuanxuan 1987, Liren et al. 1998, Tijian et al. 1998, Okabayashi et al. 1991, Ide et al. 1994, Ichikawa and Sada 2002, Ichikawa and Sada 1999). With the development of computing technology, many new researches on diffusion numerical solution emerge (Bornoff and Mokhtarzadeh-Dehgha 2001, Heinz and Dop 1999, Sawford 1991). Wind tunnel experiments can give a better simulation of wind filed and concentration filed. However, given that it costs too much money and time, wind tunnel experiment is not suitable to be used for simulating wet plume deposition. Now, the CFD (Computational Fluid Dynamics) software can be used for solving this problem.

In the 1970s, foreign scholars proposed to use CFD software for simulating the cooling tower drift diffusion. England used CFD to calculate cooling tower plume of Keystone power plant in the west of
Pennsylvania (England et al. 1973). Bergstorm used two dimensional CFD to simulate ideal drifts of cooling tower under different conditions of wind speed and directions (Bergstrom and Rezkallah, 1996). Later Bender and Derksen compared the CFD results with those of wind tunnel experiments (Bender and Derksen, 1993). They concluded that CFD can more accurately show the results of cooling tower drifts diffusion.

\section{CFD SOFTWARE INTRODUCTION}

A lot of commercial CFD software can be applied, including CFD2000, CFX-4, CFX-5, CFD Taskflow, Flow-3D, Fluent, PHOENICS, STAR-CD and STAR-CCM+.

In this paper, STAR-CCM+ is chosen. STAR$\mathrm{CCM}+$ is developed by CD-adapco. By using computational continuum mechanics algorithms and modern software engineering technology, the performance and reliability of STAR-CCM+ have been enhanced. STAR-CCM+ has a powerful mesh generator, such as Hexa, Tetra and Poly mesh grid. Compared with Tetra mesh, Poly mesh is much more effective, and solver is much faster. At present, STAR-CCM+ has been widely used in various industries such as aerospace, shipping, automobile manufacturing and environment.

In this paper, standard $k-\varepsilon$ turbulence model is used. The reason is that it converges faster and has a relatively small amount of calculation. $\varepsilon$ is fluid pulsation kinetic energy dissipation rate.

(1) Mass conservation equation

$\frac{\partial u}{\partial x}+\frac{\partial v}{\partial y}+\frac{\partial w}{\partial z}=0$

(2) Momentum conservation equation

$$
\begin{aligned}
& \frac{d u}{d t}=\frac{\partial u}{\partial t}+u \frac{\partial u}{\partial x}+v \frac{\partial u}{\partial y}+w \frac{\partial u}{\partial z}=f_{x}-\frac{\partial p}{\rho \partial x} \\
& \frac{d v}{d t}=\frac{\partial v}{\partial t}+u \frac{\partial v}{\partial x}+v \frac{\partial v}{\partial y}+w \frac{\partial v}{\partial z}=f_{y}-\frac{\partial p}{\rho \partial y} \\
& \frac{d w}{d t}=\frac{\partial w}{\partial t}+u \frac{\partial w}{\partial x}+v \frac{\partial w}{\partial y}+w \frac{\partial w}{\partial z}=f_{a}-\frac{\partial p}{\rho \partial z}
\end{aligned}
$$

(3) Standard k- $\varepsilon$ equation

$$
\frac{\partial(\rho k)}{\partial t}+\frac{\partial\left(\rho k u_{i}\right)}{\partial x_{i}}=\frac{\partial}{\partial x_{j}}\left[\left(u+\frac{u_{i}}{\sigma_{k}}\right) \frac{\partial k}{\partial x_{j}}\right]+G_{k}+G_{b}-\rho \varepsilon-Y_{M}
$$


$\frac{\partial(\rho \varepsilon)}{\partial t}+\frac{\partial\left(\rho \varepsilon u_{i}\right)}{\partial x_{i}}=\frac{\partial}{\partial x_{j}}\left[\left(u+\frac{u_{i}}{\sigma_{\varepsilon}}\right) \frac{\partial \varepsilon}{\partial x_{j}}\right]+C_{1 \varepsilon} \frac{\varepsilon}{k}\left(G_{k}+C_{3 \varepsilon} G_{b}\right)-C_{2 \varepsilon} \rho \frac{\varepsilon^{2}}{k}$

wherein:

$G_{\mathrm{k}}$ - Turbulent kinetic energy generated by layer flow velocity;

$G_{b}$ - Turbulent kinetic energy caused by buoyant effect;

$Y_{\mathrm{M}}$ - In compressible turbulence, fluctuation of excessive proliferation;

$C_{1 \varepsilon}, C_{2 \varepsilon}, C_{3 \varepsilon}$-Constant;

$\sigma_{\mathrm{k}}, \sigma_{\varepsilon}$-Prandtl number.

\section{MODEL VALIDATION}

As China lacks experiment on cooling tower wet drift, in this paper, Chalk Point power plant experiment data are used to help verify the CFD simulation results.

\section{Chalk Point Power Plant}

Power unit of Chalk Point with two natural drift cooling towers owns the capacity of 2,640 MW. The layout is a straight-line one. The distance between two towers is $152 \mathrm{~m}$. The height of each cooling tower is $124 \mathrm{~m}$, base diameter $114 \mathrm{~m}$, and outlet diameter, $54.8 \mathrm{~m}$, The following Fig. 1 shows an aerial view of Chalk Point power plant (Meroney, 2006).

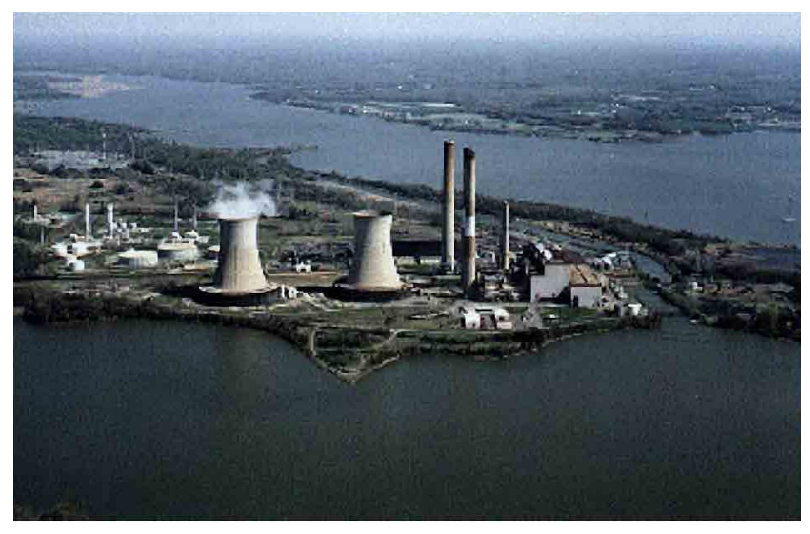

Fig. 1. Chalk Point power plant

\section{Experiments}

Despite of a large number of sodium deposition experiments, most results were also affected by simultaneous releases from other nearby stacks and towers as well as windblown brackish water sprayed from the bay. On the evening of $16^{\text {th }}$ June 1977,30 gallons of $20 \%$ Rhodamine WT (fluorescent) dye were added to the cooling tower basin water. No additional water was added to or drained from the basin during the experiment. Consequently, the only loss of dye was caused by the drift loss. The concentration of dye in the water remained constant and plant load also remained constant during the whole experiment. Source measurements reported that drift loss $\approx$ $0.002 \%$, plume temperature $=315.3 \mathrm{~K}$, ambient temperature $=295.3 \mathrm{~K}$, and exhaust velocity $=4.5 \mathrm{~m} / \mathrm{s}$. Rhodamine WT (fluorescent dye) tagged sodium source strength equaled to $1.86 \mathrm{~g} / \mathrm{sec}$. Under the humidity rate of $93 \%$ at night, the measurement for the experiment was conducted, so there was negligible droplet evaporation. Predominant winds were from the south at $350^{\circ}$; hence, building and tower wakes did not intersect in the near field. The wind speed profile was in two layers: above $100 \mathrm{~m}$, the wind speed remained nearly constant, with the averaging speed of about $8 \mathrm{~m} / \mathrm{s}$; below $100 \mathrm{~m}$, the wind speed was nearly linear with height with a mean value of about $5 \mathrm{~m} / \mathrm{s}$.

As shown in Fig.2, instruments for drift deposition were placed at $5^{\circ}$ intervals on $35^{\circ}$ arcs at distances of 0.5 and $1.0 \mathrm{~km}$ north to the cooling towers (Lucas et al. 2010). The average deposition of the dye tagged sodium droplets on the 0.5 and $1.0 \mathrm{~km}$ arcs was 1,080 and $360 \mathrm{~kg} / \mathrm{km}^{2} \cdot \mathrm{mo}$, respectively. Drift droplet sizes at the measurement stations had a mass median diameter of 340 and $260 \mathrm{~m}$ on the 0.5 and $1.0 \mathrm{~km}$ arcs, respectively. Most of the drop

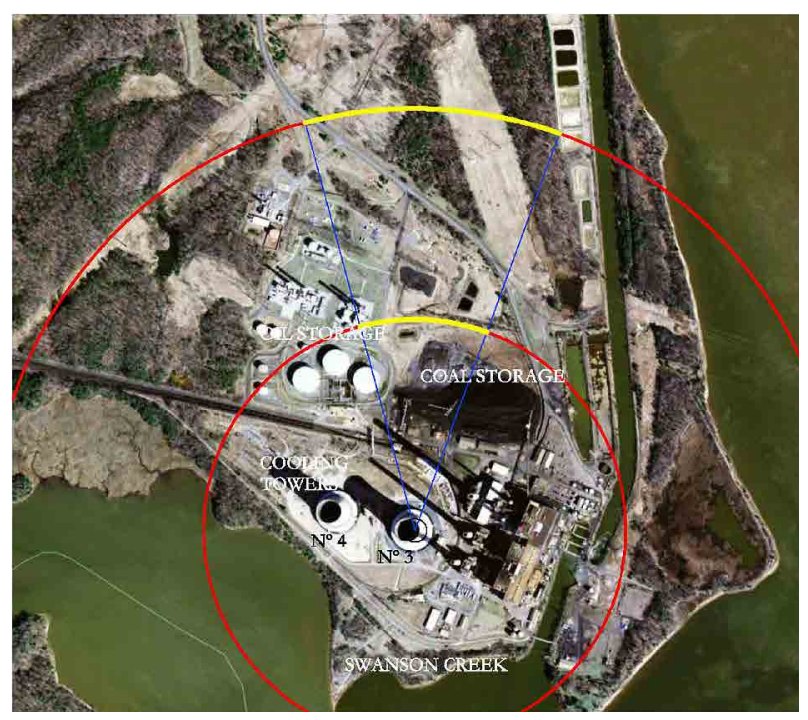

Fig. 2. ChalkPoint Experiment sampling points arrangement 
sizes were between 250 and $450 \mathrm{~m}$ on the $0.5 \mathrm{~km}$ arc and 200 and $400 \mathrm{~m}$ on the $1.0 \mathrm{~km}$ arc. In addition, plume centerline heights observed for the downwind distance range from 50 to $200 \mathrm{~m}$.

\section{D model}

In STAR-CCM+, basic parameters of the model are set as follows in Fig.3:

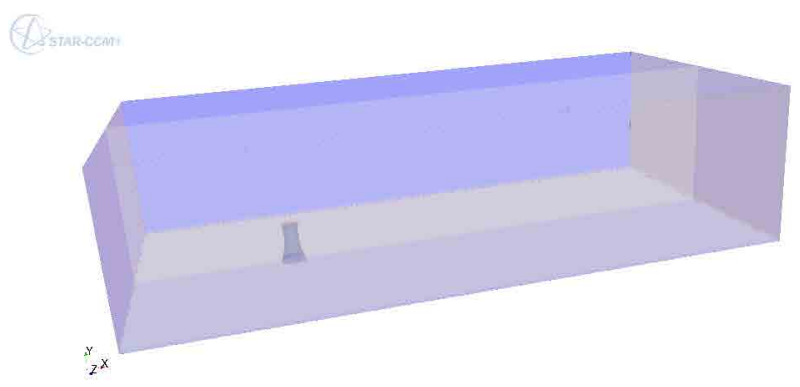

Fig. 3. ChalkPoint 3D model

Domain length is $2,000 \mathrm{~m}$, width, $1,000 \mathrm{~m}$, height, $500 \mathrm{~m}$, cooling tower height, $124 \mathrm{~m}$, base radius, 40 $\mathrm{m}$, and outset radius, $27.4 \mathrm{~m}$. Cooling tower has been located in the centerline downwind with a height of $500 \mathrm{~m}$ in the $\mathrm{x}$ axies. The model is as below.

Polyhedral mesh is used, cooling tower volume mesh grid is $4 \mathrm{~m}$, for the other grid, its size is $50 \sim 100$ $\mathrm{m}$, with a total number of 600,000 grids as shown in Fig.4:

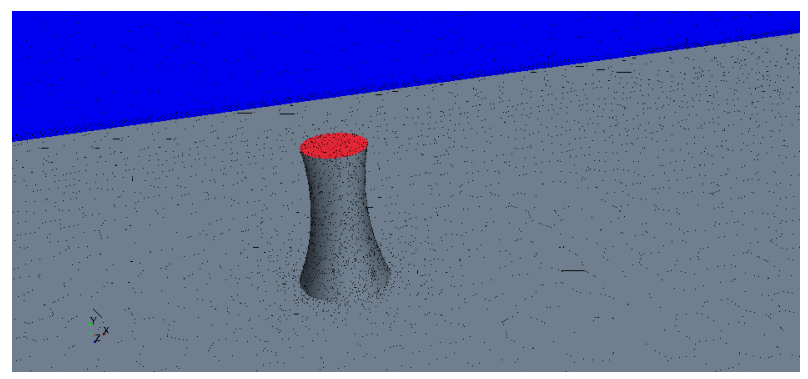

Fig. 4. ChalkPoint 3D grid model

\section{Boundary conditions}

Boundary conditions in STAR-CCM+ are shown in Fig.5.

The measured temperature for the inlet is $295.3 \mathrm{~K}$. The inlet velocity is exponential distribution within the height of $100 \mathrm{~m}$; above $100 \mathrm{~m}$, the constant velocity speed is $8 \mathrm{~m} / \mathrm{s}$. Fig. 6 refers to the inlet wind profile.

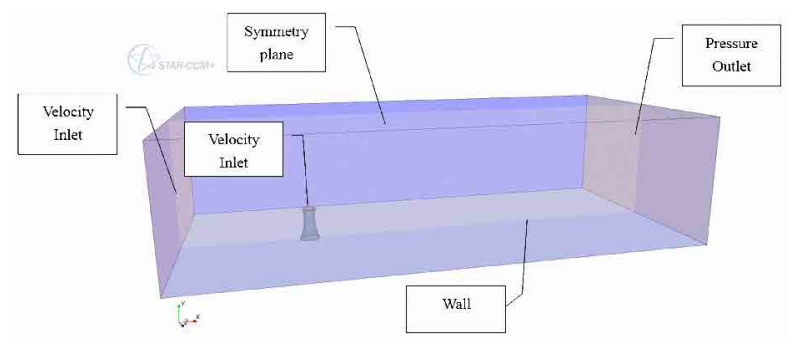

Fig. 5. Boundary conditions

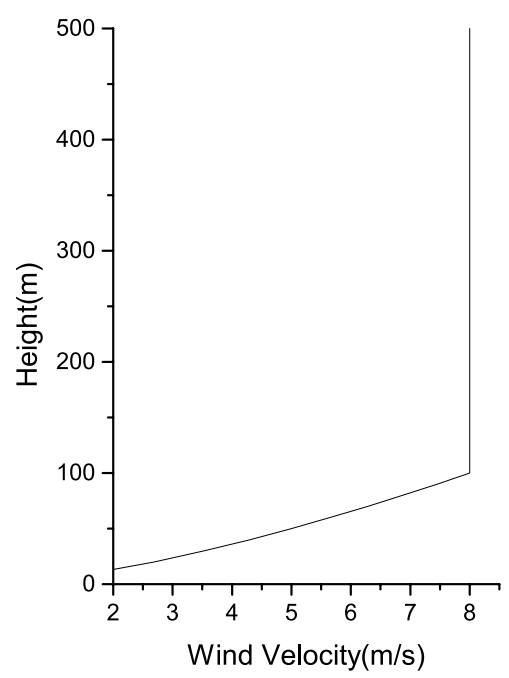

Fig. 6. Inlet wind profile

$v=0.3523 \cdot z^{6781.0}$

Surface roughness is $0.5 \mathrm{~m}\left(Z_{0}=0.02 \mathrm{~m}\right)$.

Both sides of the domain are well, and top is a symmetry plane.

Use standard $k-\varepsilon$ model and Lagrangian multiphase flow model.

Cooling tower drift outlet velocity is $4.5 \mathrm{~m} / \mathrm{s}$, turbulence intensity, $10 \%$, turbulence length, $25 \mathrm{~m}$, outlet temperature, $315.3 \mathrm{~K}$.

As humidity remains very high during the experiment period, thus, in the calculation, the evaporation of the droplets should be neglected.

For the Lagrangian multiphase flow model in the $\mathrm{STAR}-\mathrm{CCM}+$, the particle material means water droplets.

Particle mass velocity is $0.328 \mathrm{~kg} / \mathrm{s}$.

Plume drift initial velocity is $4.5 \mathrm{~m} / \mathrm{s}$.

The distributed particle diameter is Rosin-Rammle which is shown as Fig.7. 


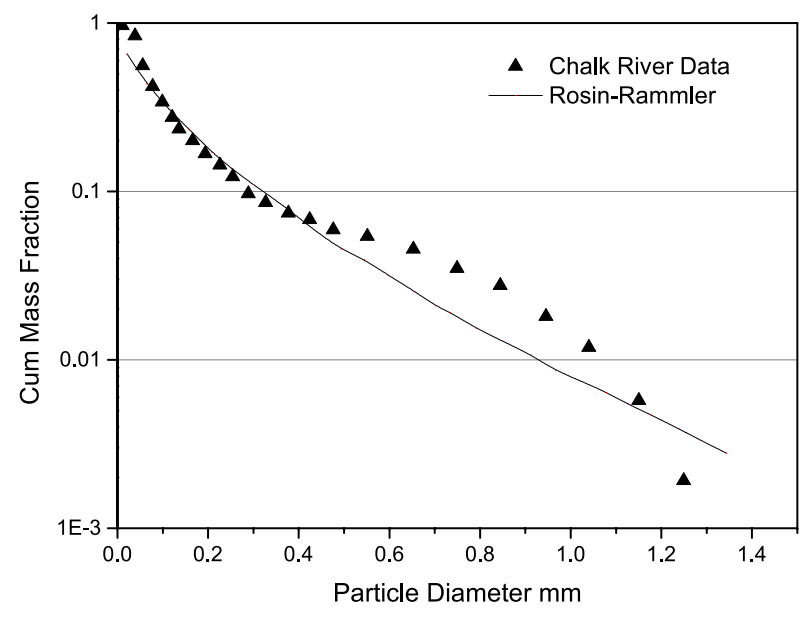

Fig. 7. ChalkPoint Particle diameter distribution

\section{Analysis}

(1) Height validation for cooling tower plume lift

In this paper, CFD simulation results of plume lift height in different distances' downwind are compared based on Chalk Point experiment data and Briggs formula calculation results from Hanna, which is shown as Fig.8.

The above figure clearly shows that CFD simulation results conform to the data from the Chalk Point experiment within 50-200 m. Compared with Briggs plume lift formula $\left(H=1.6 F^{1 / 3} x^{2 / 3} / U, F=2100 \mathrm{~m}^{4} / \mathrm{s}^{3}\right.$, $U=8 \mathrm{~m} / \mathrm{s}$ ), Briggs' results are more accurate in 200 $\mathrm{m}$. In the case of other distances, Briggs' results are

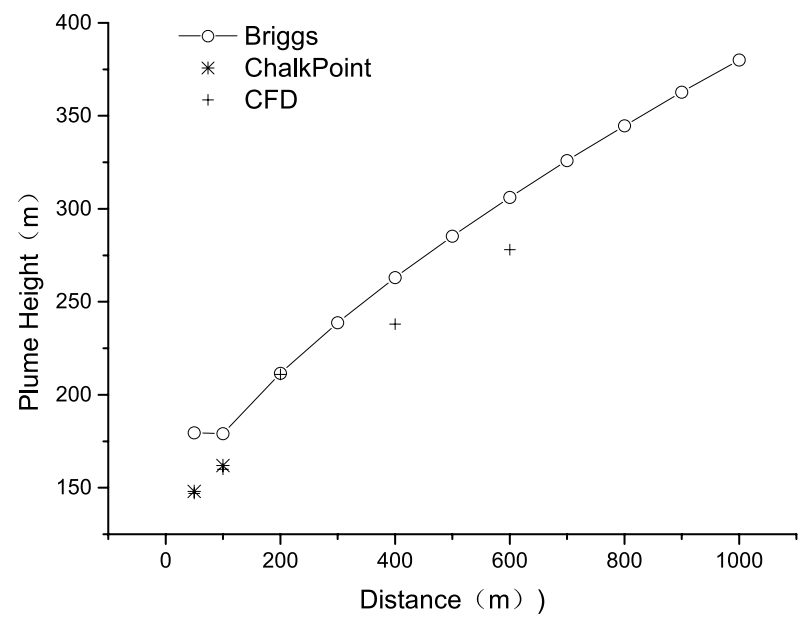

Fig. 8. Cooling tower plume lift height comparison generally higher than the experiment data of CFD and Chalk Point.

Cooling tower plume diffusion locus is shown as Fig.9:

(2) Wet deposition validation

In Chalk Point experiment, wet deposition was monitored in downwind distance of $0.5 \mathrm{~km}$ and 1.0 $\mathrm{km}$. Fig. 10 shows the comparison between results from the CFD and experiment data from Chalk Point.

In Chalk Point experiment, only two distance data were monitored. All the data have already been shown above. CFD result is about two times higher than the data from Chalk Point experiment at $500 \mathrm{~m}$. In the far region, both become relatively close. The main reason is that there is difference in the particle size distribution as such difference can affect wet deposition distribution. Based on CFD results, the maximum value appears at $620 \mathrm{~m}$ and wet deposition amount is $6.9 \mathrm{E}-07 \mathrm{~kg} / \mathrm{m}^{2} \cdot \mathrm{s}$. Fig.11 is the wet deposition distribution of CFD simulation.

\section{CASE STUDY}

Two inland sites in China are chosen as places for research. These sites are Taohuajiang nuclear power plant in Hunan province and Pengze nuclear power plant in Jiangxi province respectively.

\section{Sites 3D model}

Based on sites layout, solidworks and terrain data were used for 3D model. Fig.12 and Fig.13 are two sites 3D models in CFD software respectively.

Domain size is $20 \mathrm{~km} \times 20 \mathrm{~km}$. In the vertical direction, height is $4,000 \mathrm{~m}$ with 50 layers. The height of each layer will increase by 1.2 based on that of the previous layer. The boundary layer height is 2 $\mathrm{m}$. Nest grid is used with grid size ranging from $3 \mathrm{~m}$ to $200 \mathrm{~m}$, and building surface size is $4 \mathrm{~m}$. The total number of grids is 2,500,000 3,000,000. Fig.14 and Fig. 15 show the grids of 3D models respectively.

\section{Boudary conditions}

Inlet wind profile is exponentially distributed.

$u=u_{70} \times\left(\frac{Z}{70.0}\right)^{p}$

$u$ is wind velocity, $\mathrm{m} / \mathrm{s} ; u_{70}$ is wind velocity at the height of $70 \mathrm{~m}$. For Taohuajiang nuclear power plant, $u_{70}$ is $2.3 \mathrm{~m} / \mathrm{s}$; for Pengze nuclear power plant, $u_{70}$ is $5.2 \mathrm{~m} / \mathrm{s} ; Z$ is height, $\mathrm{m} ; p$ is exponent number of 0.25 for Taohuajiang and 0.179 for Pengze respectively in D stability. 


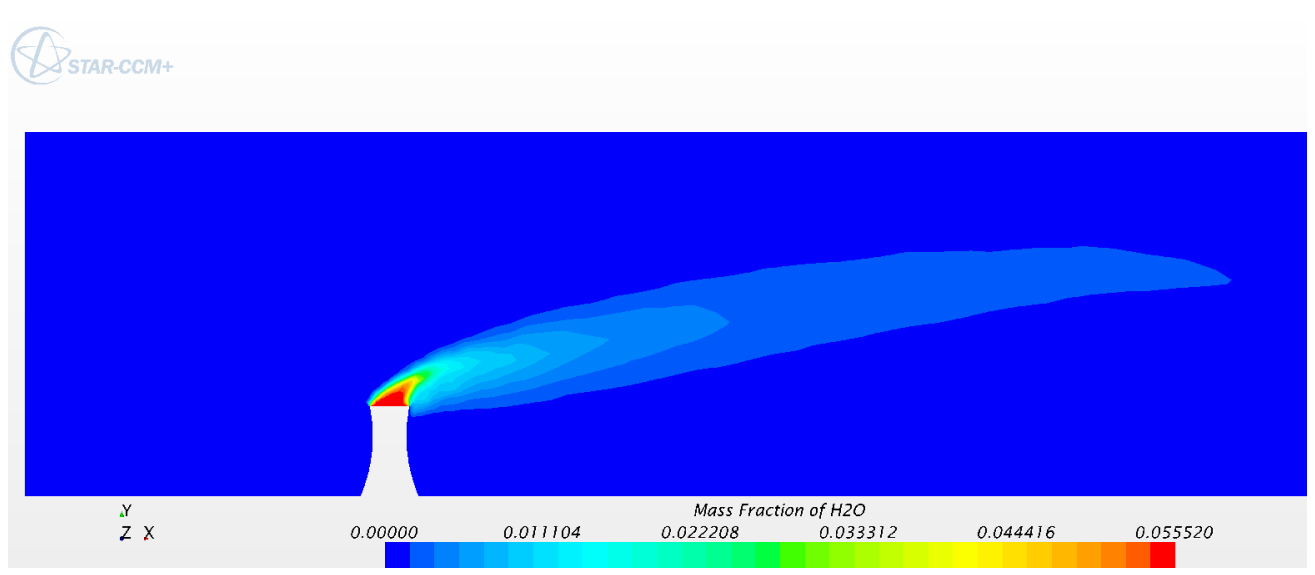

Fig. 9. Cooling tower plume diffusion locus

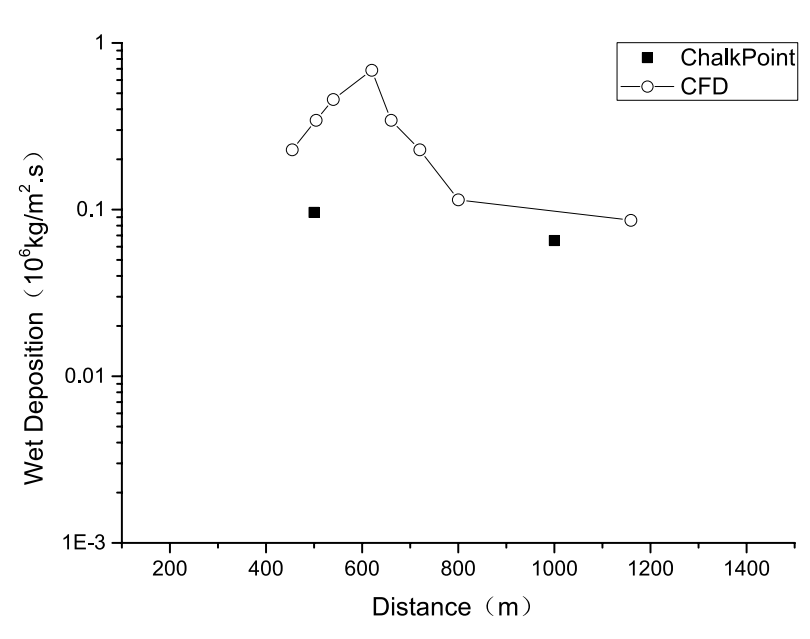

Fig. 10. Wet deposition data comparison

Turbulence intensity: turbulence intensity is 0.2 below $400 \mathrm{~m}$ and 0.1 above $400 \mathrm{~m}$, for Taohuajiang; turbulence intensity is 0.1 below $100 \mathrm{~m}$ and 0.05 above $100 \mathrm{~m}$ for Pengze.

Surface roughness is $0.3 \mathrm{~m}$; Cooling tower drift velocity is $4.35 \mathrm{~m} / \mathrm{s}$; Cooling tower drift temperature is $30.33^{\circ} \mathrm{C}$; Air temperature is $16.9^{\circ} \mathrm{C}$ for Taohuajiang and $16.5^{\circ} \mathrm{C}$ for Pengze; Mass rate is $0.455 \mathrm{~kg} / \mathrm{s}$; Particle diameter distribution is Rosin-Rammler; Mass fraction is $5.552 \%$.

\section{Cooling tower design parameters}

(1) Taohuajiang nuclear power plant

Design parameters for Taohuajiang nuclear power plant cooling tower are shown below. (Table I)

(2) Pengze nuclear power plant

Pengze nuclear power plant cooling tower design parameters are shown below(Table II).

\section{Calculation results}

(1) Taohuajiang nuclear power plant

Fig.16 is centerline wet deposition results of CFD

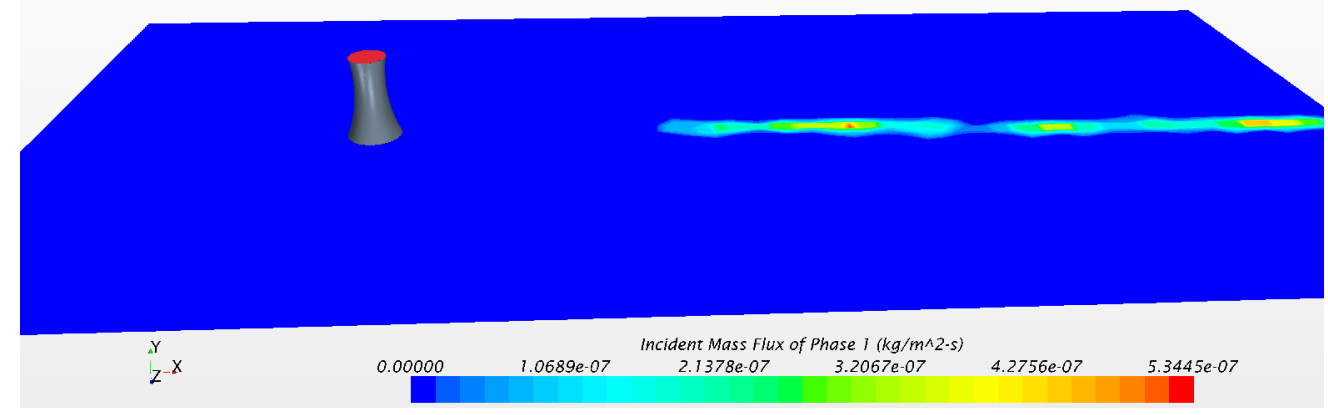

Fig. 11. Cooling tower wet deposition distribution in CFD 


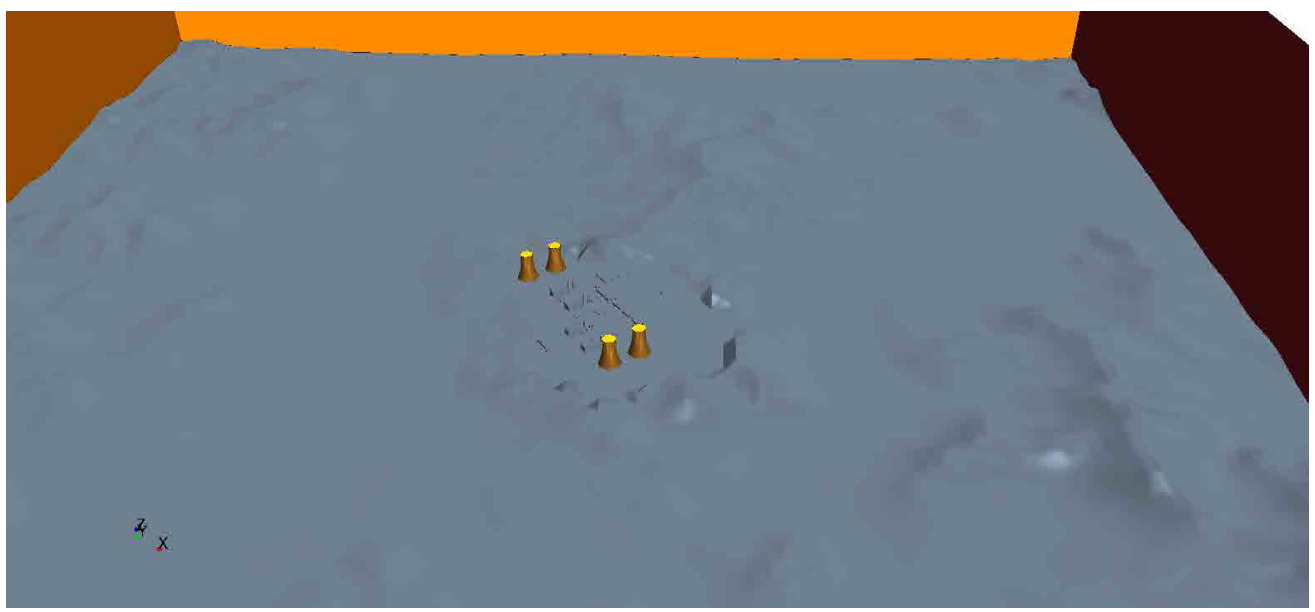

Fig. 12. 3D model of Taohuajiang nuclear power plant

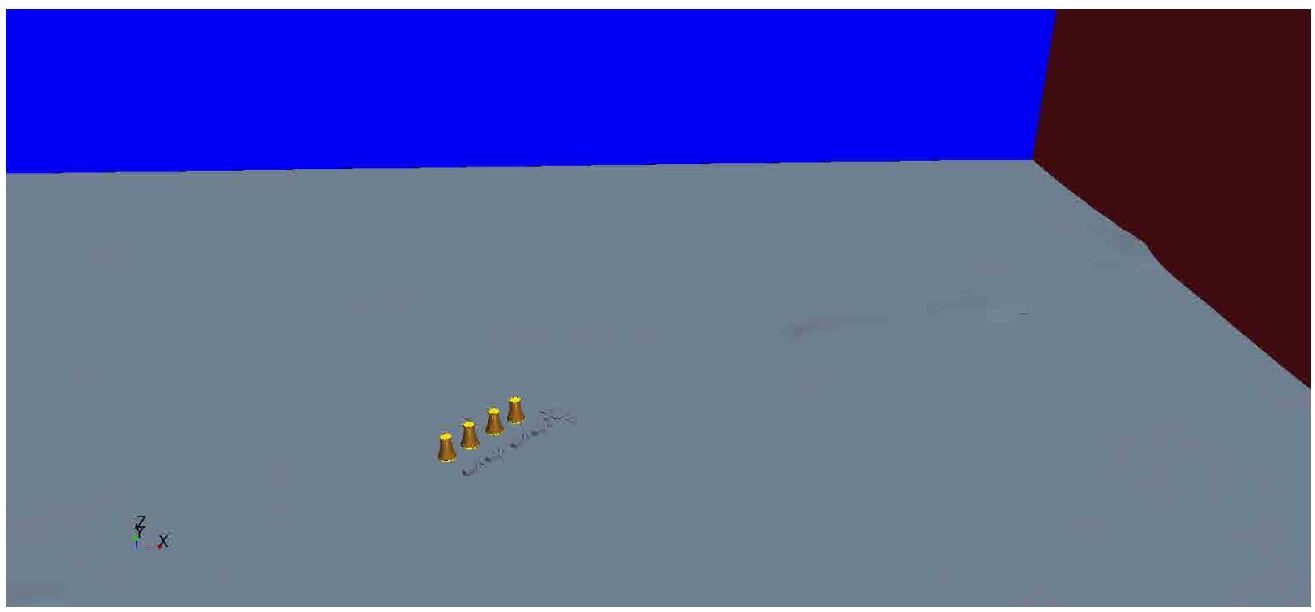

Fig. 13. 3D model of Pengze nuclear power plant

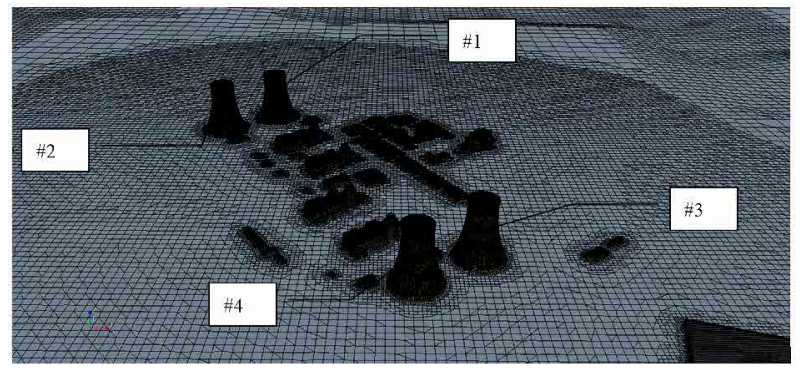

Fig. 14. 3D grid model of Taohuajiang nuclear power plant

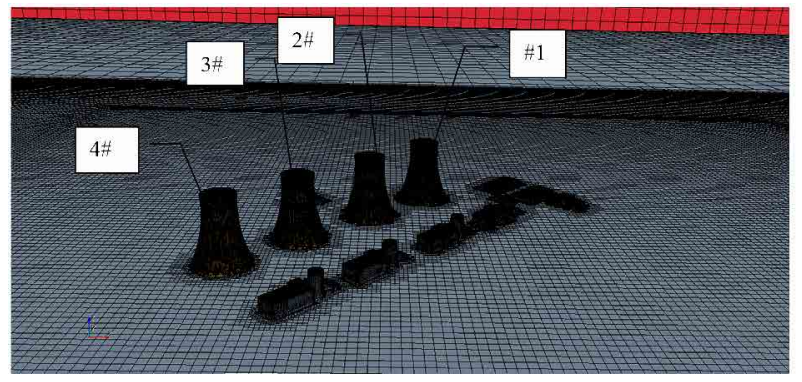

Fig. 15. 3D grid model of Pengze nuclear power plant 
TABLE I. TAOHUAJIANG COOLING TOWER DESIGN PARAMETERS

\begin{tabular}{lc}
\hline Parameters & Value \\
\hline Base diameter & $158.8 \mathrm{~m}$ \\
Height & $200 \mathrm{~m}$ \\
Outlet diameter & $95.74 \mathrm{~m}$ \\
Throat diameter & $92.1 \mathrm{~m}$ \\
Two towers distance & $110 \mathrm{~m}$ \\
Eliminator efficiency & $95 \%$ \\
\hline
\end{tabular}

TABLE II. PENGZE COOLING TOWER DESIGN PARAMETERS

\begin{tabular}{lc}
\hline Parameters & Value \\
\hline Base diameter & $168.66 \mathrm{~m}$ \\
Height & $215 \mathrm{~m}$ \\
Outlet diameter & $102.70 \mathrm{~m}$ \\
Throat diameter & $99.0 \mathrm{~m}$ \\
Two towers distance & $110 \mathrm{~m}$ \\
Eliminator efficiency & $95 \%$ \\
\hline
\end{tabular}

and SACT model. Generally speaking, CFD results are two times larger than those of SACTI model. The main reason is that in this paper, SACTI uses hourly data of the whole year, but single wind direction and wind speed are applied to CFD. At NO.1 cooling tower downwind distance of $159 \mathrm{~m}, \mathrm{CFD}$ maximum wet deposition value is $4.91 \mathrm{E}-06 \mathrm{~kg} / \mathrm{m}^{2} \cdot \mathrm{s}$. At NO.1 cooling tower downwind distance of $200 \mathrm{~m}$, SACTI maximum wet deposition value is $1.23 \mathrm{E}-06 \mathrm{~kg} / \mathrm{m}^{2} \cdot \mathrm{s}$, indicating that CFD results are slightly accurate than those of SACTI.

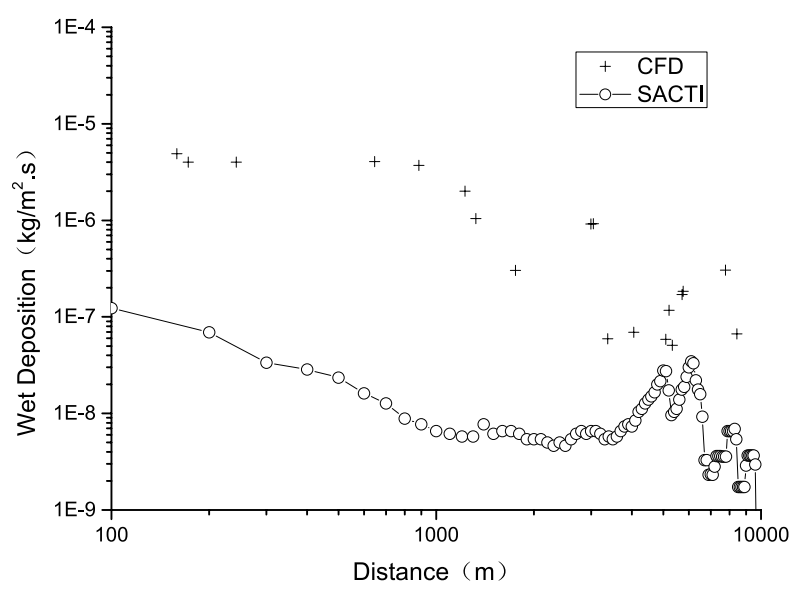

Fig. 16. Wet deposition distribution in the downwind centerline of Taohuajiang nuclear power plant

Fig.17 shows the cooling tower diffusion locus. It can be seen, in the near area that as large particle size droplets rapidly sink to the ground, and the small size particle can drift farther.

(2) Pengze nuclear power plant

Fig.18 is centerline wet deposition results of CFD and SACT model. In the near area, CFD results are close to those of SACTI model. When it approaches $2 \mathrm{~km}$ outside, SACTI results decrease much more rapidly. Within $1 \mathrm{~km}, \mathrm{CFD}$ results are slightly higher than those of SACTI model, which is mainly due to the impact of cooling tower provided in CFD.

CFD maximum wet deposition value is $2.48 \mathrm{E}-$ $08 \mathrm{~kg} / \mathrm{m}^{2} \cdot \mathrm{s}$, which appears at NO.1 cooling tower downwind distance $300 \mathrm{~m}$. SACTI maximum wet deposition value is $9.65 \mathrm{E}-09 \mathrm{~kg} / \mathrm{m}^{2} \cdot \mathrm{s}$, at NO.1 cooling tower downwind distance $900 \mathrm{~m}$. CFD simulation

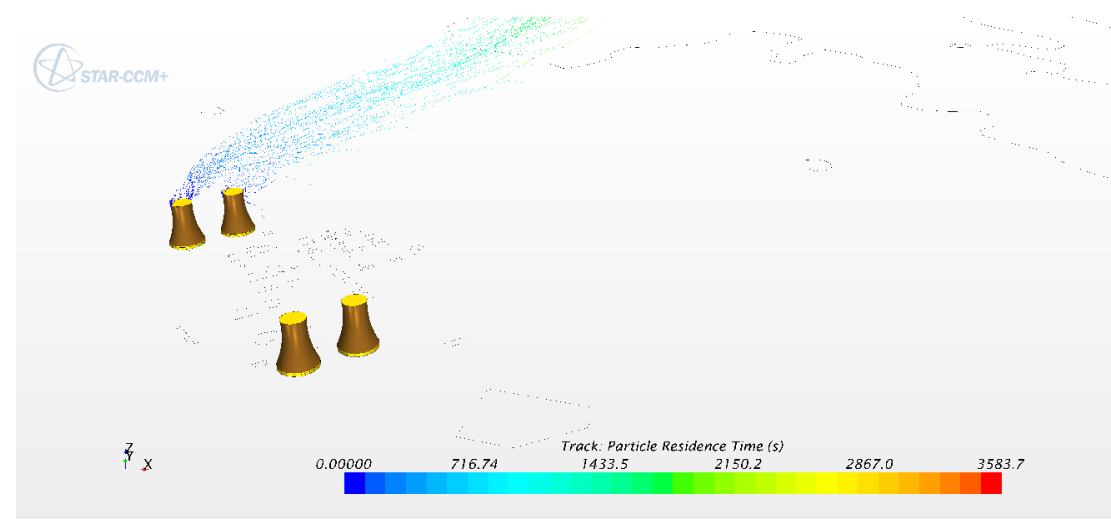

Fig. 17. Diffusion locus of the Taohuajiang nuclear power plant cooling tower 


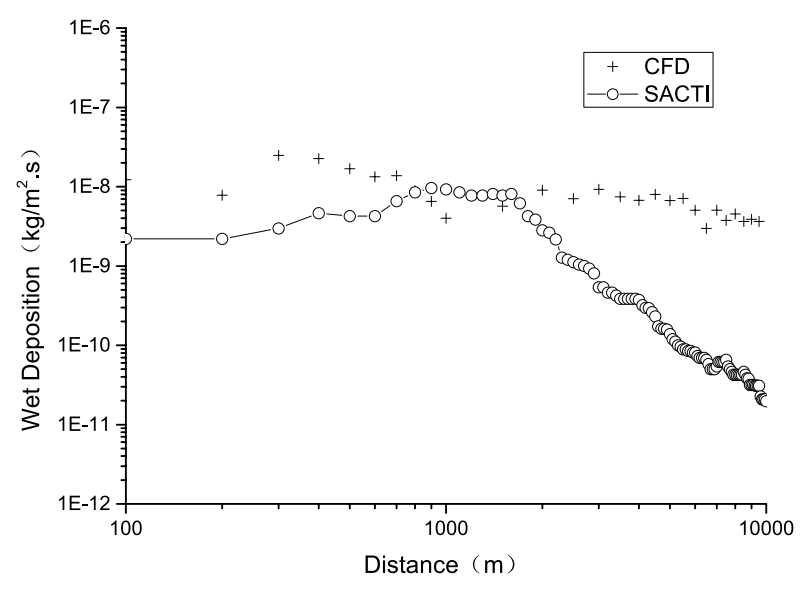

Fig. 18. Wet deposition distribution in the downwind centerline of Pengze nuclear power plant

results are higher than those of SACTI in the near region because of the downwash effects of the cooling tower.

Fig.19 shows the cooling tower diffusion locus of Pengze nuclear power plant. It is clear that in the near area, under the blocking effect of cooling towers, part of particle droplets rapidly sink to the ground.

\section{CONCLUSION}

Chalk Point experiment data are used to validate the simulation ability of CFD software. In conclusion, at $500 \mathrm{~m}, \mathrm{CFD}$ can better simulate plume lifting process and CFD can achieve wet deposition results two times as well as those from the Chalk Point experi- ment. In the far region, both become relatively close. The main reason is that particle size distribution can effect wet deposition distribution. Generally speaking, CFD can help better refelect a vivid process of cooling tower plum dispersion and deposition. When there are no other field data, CFD will be a powerful tool in assessing impact on environment.

Pengze and Taohuajiang nuclear power plants are used as places for research. Conclusions show that CFD results of wet deposition conform to the SACTI experiment in the near area. The maximum value of CFD appears much earlier than that of SACTI because of the blocking effect of cooling towers. In the far area, SACT results decrease dramatically.

\section{OUTLOOK}

Although CFD software can better simulate cooling tower plume dispersion and deposition, due to the limited calculation ability, hourly meteorological data of the whole year in the CFD software cannot be used. In subsequent studies, boundary conditions is optimized and reasonable meteorological classification is made, so CFD software has the ability to simulate multiple meteorological data.

After further development, this study can also be applied in salt deposition calculation, which has a long last meaning for assessing environmental impact of the seawater cooling tower.

Plume shadow of cooling tower drift is also affected by season, sun angle and location. However, the CFD software has not included the aforementioned factors, which are important for the future.

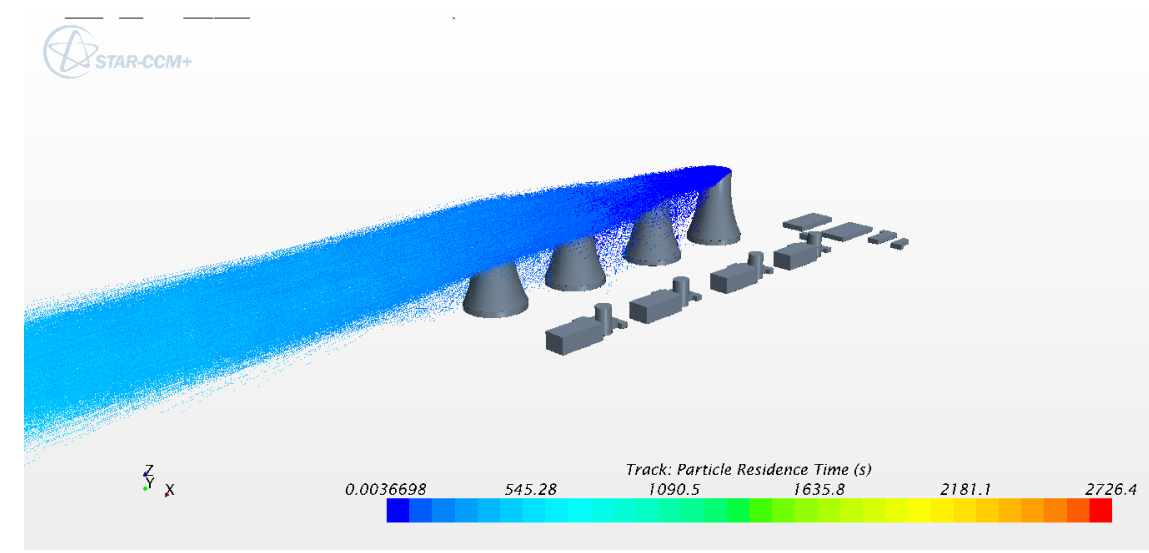

Fig. 19. Diffusion locus of Pengze nuclear power plant cooling tower 


\section{ACKNOWLEDGMENT}

This research was financially supported by China Advanced Nuclear Power Standard System Research (2017ZX06004001).

\section{REFERENCES}

Ammar N.R. and Farag A.I. (2016). CFD modeling of syngas combustion and emissions for marine gas turbine applications. Polish Maritime Research. 23(3), 39-49.

Bender D.J., Derksen D.J. and Rezkallah K.S. (1993). Numerical study of wind flow over a cooling tower. Journal of Wind Engineering and Industrial Aerodynamics. 46-47, 657-664.

Bergstrom D.J. and Rezkallah K.S. (1996). A study on the effects of wind on the air intake flow rate of a cooling tower: Part 2. Wind wall study. Journal of Wind Engineering and Industrial Aerodynamics. 64, 61-72.

Bornoff R.B. and Mokhtarzadeh-dehgha M.R. (2001). A numerical study of interacting buoyant cooling-tower plumes. Atmospheric Environment. 35, 589-598.

England W.G., Teuscher L.H. and Taft J.R. (1973). Cooling tower plumes-defined and traced by means of computer simulation models. Cooling Tower Institute Annual Meeting, Houston TX-January. 29-31, 41.

Heinz S. and Dop H.V. (1999). Buoyant plume rise described by a lagrangian turbulence model. Atmospheric Environment. 33, 2031-2043.

Ichikawa Y. and Sada K. (1999). An evaluation method of the topographical effects on exhaust gas dispersion using a numerical model. Komae Research Laboratory Report, No. T98010. $7^{\text {th }}$ Int. Conf. on Harmonisation within Atmospheric Dispersion Modelling for Regulatory Purposes.

Ichikawa Y. And Sada K. (2002). An atmospheric dispersion model for the environment impact Assessment of thermal power plants in Japan-a method for evaluation topographical effects. Journal of the Air \& Waste Management Association. 52, 313-323.
Ide Y., Ohba R. and Okabayashi K. (1994). Development of overlapping modeling for atmospheric diffusion. Atmospheric Environment. 28(11), 1925-1932.

Liren X., Tijian W. and Zongkai L. (1998). An improved model of the boundary layer. China Environment Science. 18(1), 43-47.

Lucas M., Martínez P.J., Ruiz J., Kaiser A.S. and Viedma A. (2010). On the influence of psychrometric ambient conditions on cooling tower drift deposition. International Journal of Heat and Mass Transfer. 53, 594-604.

Meroney R.N. (2006). CFD prediction of cooling tower drift. Journal of Wind Engineering and Industrial Aerodynamics. 94, 463-490.

Nguyen K.C., Noonan J.A., Galbally I.E. and Physick W.L. (1997). Predictions of plume dispersion in complex terrain: eulerian versus lagrangian models. 31(7), 947-958.

Okabayashi K., Ide Y., Takahashi H., Kane N., Okamoto S. and Kobayashi K. (1991). A new wind tunnel technique for investigating gas diffusion behind a structure. Atmospheric Environment. 25A(7), 1227-1236.

Poppenga S.K. and Worstell B.B. (2016). Hydrologic connectivity: Quantitative assessments of HydrologicEnforced drainage structures in an elevation model. Journal of Coastal Research. (76), 90-106.

Sawford B.L. (1991). Reynolds number effects in Lagrangian stochastic models of turbulent dispersion. Phys Fluids A. 3(6), 1577-1586.

Tijian W., Zhaobo S. and Zongkai L. (1998). Chinese regulation atmospheric diffusion model and its comparison with other models. Environmental Science. 11(6), 9-12.

Well J.C. and Brower R.P. (1984). An updated Gaussian plume model for tall stacks. Journal of the Air Pollution Control Association. 34, 818-827.

Zhishan W. and Jinping H. (1998). Environment protection and sanitation standards implementation manual. Beijing: China Building Industry, 73-105.

Zongkai L. and Xuanxuan Z. (1987). Mechanical turbulence limited thermal plume buoyancy lift model. Science in China Series B, 7, 780-788. 